\title{
Physical Education Reform in Higher Vocational College Based on the Top-Down Design
}

\author{
Jun Zheng \\ Nanjing Institute of Railway Technology, Nanjing, 210031, China
}

Keywords: Higher vocational colleges, Physical education, Top-down design

\begin{abstract}
This article intends to begin with the problem of lacking overall consideration of the physical education curriculum reform in higher vocational colleges, starting from the concept and perspective of the top-down design, discuss on the direction of physical education reform in higher vocational colleges, and analysis the main content and requirements of physical education reform based on the top-down design, which includes integration of personnel training program and construction of high level sports teachers, construct the new curriculum system and cultivate the sports culture and so on.
\end{abstract}

\section{Introduction}

Decision of the State Council on accelerating the development of modern vocational education once point out: "Accelerate the construction of modern vocational education system, deepen integration of production and teaching, cooperation between college and enterprise, cultivate hundreds of millions of high-quality workers and technical talents". Higher vocational education takes on the mission of the times for training high quality technical talents for production, management, service on the first line, and physical education is an important part of the personnel training in higher vocational colleges. Just like what Xi Jinping stressed during his visit for Chinese sports delegation which attend the Nanjing Youth Olympic Games, if the youth in China is strong then China is strong. Youth strong includes many aspects, such as Ideological and moral, academic performance, innovation ability, hands-on ability, physical health, physical strength and sports spirit .Hence, the importance of physical education in promoting the development of youth is self explanatory, however, there are still many problems in physical education of higher vocational colleges, there is still is also a long way to go for reform.

\section{Put forward the problem}

In recent years, the health status of students in higher vocational colleges is not optimistic, internet is increasingly squeezing the students' sports time, smoking, addicted to online games, sleeping late in the morning and do not eat breakfast and other bad habits as the shadow follows the form, student overweight, obesity rates are rising, and the more high grade of the students the more bad health level are of them. We often see such a scene, many students faint because physical weaknesses in the college military training. And in the national vocational skills competition, many events require several hours continuous operation, many players are not lost in technical skills but lost in the physical fitness. With such bad physical quality how can they have a good performance in workplaces? How can they take responsibility for the future family? How can they take the responsibility of national rejuvenation?

Though the cause of the above phenomenon is complex, however, we should firstly introspect on the problems of physical education in higher vocational colleges. In the implementation of the research of this topic, we find that in recent years, higher vocational colleges attach great importance to the reform of physical education curriculum, however, the reform general is lack of overall consideration and scientific design, which caused the phenomenon of treat the head when the head aches and treat the foot when the foot hurts (no overall plan for a fundamental transformation), thus 
the reform of physical education curriculum is not good, function of physical education is difficult to achieve entirely.

\section{Countermeasure analysis}

\section{Accurate grasp of the direction of physical education reform in Higher Vocational Colleges.}

In order to solve the above problems and play the unique role of physical education in the cultivation of high quality technical talents, we must promote the reform of physical education in higher vocational colleges, which is a complicated system project, we have to accurately grasp the direction of reform firstly in order to achieve the effect.

Based on the needs of students' comprehensive development

Since the essence of education is to promote the comprehensive development of human, then the development demand of students is the origin of education reform . Liu Yandong stressed at national school sports work forum on July 28th, strengthening the school sports work is an important way to promote the school to return to the Education origin and enhance students' comprehensive development, we need to make students a strong physique and healthy personality through school physical education and develop the habit of lifelong physical exercise and healthy life style . This speech made a clear explanation of the need for physical education in the process of development of the students, it also point out the starting point of physical education reform in higher vocational colleges.

Conform to the trend of international sports education

Higher vocational talents cultivation is the trend of internationalization, physical education should also be in line with international standards, therefore, physical education reform must conform to the trend of internationalization. From the development of physical education in Europe, America and Japan we can see that our higher vocational education reform should consider the following aspects, (1)Socialization of physical education, pay attention to education of students' social adaptability, make good preparation for students' integration into society; (2) The life of physical education , start with the idea of "health first", pay attention to cultivate students' physical exercise habits and healthy life style, let students benefit from it for lifetime;(3) Spiritualization of physical education, pay more attention on sports to play the role on emotional education, ideological and political education, personality education, aesthetic education and some other aspects, help students build a spiritual world to do useful exploration;(4) Individualization of physical education , pay more attention to the individual differences of students, meet students individual demand for physical education.

\section{Reflect the characteristics of higher vocational education}

Most of the students in higher vocational colleges consider themselves as "the loser of the college entrance examination ", lack of self confidence is a relatively common psychological status, the students have a very strong desire for successful experience and the establishment of confidence, and physical education has a unique advantage in cultivation of students' perseverance, overcome the difficulties of setbacks and experience success, this is the must pay attention problem for higher vocational education reform. Secondly, the vocational characteristics of higher vocational education is the biggest difference from ordinary undergraduate education, therefore, in the design of physical education reform we should also fully consider its professional skills and professional skills as well as the needs of professional positions, create curriculum and related educational programs to meet the needs of professional post.

\section{Work well for the top level design of physical education reform in higher vocational colleges.}

Since the reform of physical education in higher vocational colleges is a complicated system engineering, so we should start with the scientific top level design, using the method of system theory as a guide, considerate various factors and their relationship, concentrate on the main points and make sure once the key link is grasped, everything else falls into place. 
The concept of Top-Down Design

Top-Down Design is the terms in the field of Engineering Technology, the original meaning in engineering is to consider all levels of the project and factors, trace out by history and bear in mind the total situation, and find solution to the problem at the highest level. Top-Down Design make use of method of system theory, make an overall planning for a task or every aspect, level and element of some project from a overall perspective ,"put the object in the system and have an inspection for it, always focus on the whole and the part, the connection between the whole and the external environment, the relationship between the interaction and mutual restraint, and make a comprehensive and precise study of the object ." Focus on effective resources and achieve the goal efficiently and fast. There are three characteristics of Top-Down Design, the first is Top-Down finality, Top-Down Design is the design method starts from high-end to low-end, core ideas and goals are derived from the top level, so the top level decides the low level and the high-end decides the low-end ; the second is overall relevance, Top-Down Design emphasizes the connection, matching and organic cohesion about relationship of the core concept and the top target among the internal elements; The third is practical operability, the basic requirement of design is concise and clear formulation, design results have practical feasibility, thus Top-Down Design should be implementable and operable.

Necessity of physical education reform in higher vocational colleges starts from the Top-Down Design

Sports education is an independent system , which covers educational ideas, curriculum system, curriculum implementation, hardware facilities, teaching staff, sports and scientific research and some other aspects, there are mutual support and influence between these factors. "Physical education curriculum is the educational process that promote the development of physical and mental, ideological and moral education, culture science education, organism combination of life and physical education and physical activity; It is an important way to implement quality education and cultivate the comprehensive talents." This expression fully shows the relationship among the physical education ,school physical education curriculum and other aspects of education, physical education is an important part of the whole school education, the process of physical education is the organic combination and interaction process among moral education, intellectual education, aesthetic education, life education, the function of physical education depends on the mutual penetration and support from other aspects of education.

Therefore, no matter from the overall higher vocational education system, or from the subsystem of physical education, the reform of physical education must start from the overall situation and the entirety, focus on the relationship between the whole and the part, the whole and the external environment, comprehensively and precisely cogitate ideas and measures of reform from interaction, mutual restriction relations, starting from the top-down design to ensure the correctness and validity of reform . Otherwise, the reform is only fragments and on the basis of one-sided viewpoint.

\section{The main aspects of the top-down design of physical education reform in Higher Vocational Colleges}

\section{Seize the fundamental talent cultivation program.}

No matter the school leadership or physical education teachers should recognize that if higher vocational colleges want to cultivate high quality technical skills talents, they should develop citizens with good physical quality firstly. Therefore, higher vocational colleges should take physical education reform as an important part of educational reform, together with professional skills training, ideological and political education, design systematically and planning overall, integrate physical education thought and goal with school running idea, school development plan and various professional talents training program, carry out reform of comprehensive personnel cultivation mode, and achieve the goal of higher vocational education talents cultivation.

\section{Based on the core system of curriculum establishment.}

Curriculum is the ultimate carrier for the implementation of Physical Education reform ,therefore, curriculum system construction is the core issue of the top-down design of physical education reform 
in higher vocational colleges. and the curriculum system construction should pay attention to following four aspects:(1) What kind of idea will guide and run through the course system construction? This is the guiding ideology and will determine the direction of the course system construction.(2) Perfection of the value function of higher vocational physical education curriculum , in theory, the perfection of physical education curriculum value will greatly promote the realization of the diversified education function in practice. (3) Construction of physical education curriculum system in higher vocational colleges, starts from the needs of students' growth and career development, break through the time and space bound of traditional physical education curriculum, enrich the content of Physical Education Curriculum , innovative teaching and learning model , and construct large physical education curriculum system in higher vocational colleges. (4) Building characteristics of higher vocational college physical education curriculum, starting from the essential attribute of Higher Vocational education, consider the combination of physical education curriculum and professional skills, professional post requirements, bring forth the new through the old, create various kinds of physical education courses with vocational colleges characteristic and sports exercise program for general public.

\section{Focus on the construction of teachers.}

Teachers are the key element for reform of physical education curriculum, because physical education teachers are the implementation subject of the curriculum. No matter how good the idea and design is , if there is no high level teachers to implement and create, it will be just an empty talk and castles in the air, therefore, in the top-level design of higher vocational colleges physical education reform , construction of teacher team should be considered as a key factor. Top-down design curriculum implementation requires a new type of physical education teacher, they must have a strong curriculum sense. Only when teachers have a strong curriculum sense, can they have a profound understanding of the meaning of the curriculum objectives, the reason for top-down design to choose the current contents, and understanding the inherent requirements of the curriculum elements in the curriculum design. Only when teachers have a strong curriculum capacity, can they make appropriate adjustments for curriculum design according to the specific curriculum implementation situation during the course implementation process, and make compensate for the defects of the design itself, organize and implement the teaching on the viewpoint of the curriculum designers conscientiously, and find out the incompatible elements of the courses and make targeted adjustments. Briefly speaking, only physical education teachers have a strong curriculum sense and curriculum capacity, can they ensure the smooth implementation of physical education curriculum. a new type of physical education teachers should change from the curriculum materials executor to the participants of the curriculum development, from the sports skills facilitator to students' healthy growth promoter and from the controller of physical education to students' active learning guide.

\section{Cultivation of sports culture soil in higher vocational colleges.}

The construction of modern vocational college culture is the important task of higher vocational colleges, sports culture is an important part of college culture. Now, more and more vocational colleges begin to pay more attention to the construction of college culture, they involve campus culture construction as a sub program into the college career development plan. We should seize this opportunity to design sports culture construction in higher vocational colleges from a strategic height of the culture construction, and make an organic integration into the campus culture .

When sport ascends as a culture, the values advocated by the sports education can give students a subtle influence, this influence can guide students' behavior and implement the most effective education. At that time, the health concept will be really popular and physical exercise will become a consciousness life of students.

\section{Acknowledgments}

The thesis is a part of the research project of Jiangsu province education teaching reform, subject name: Theoretical exploration and practice of physical education curriculum construction in higher vocational colleges based on the top level design, project number: 2013JSJG373. 


\section{References}

[1] Notice issued by the Ministry of Education, Guiding outline of physical education curriculum in colleges and universities of China (teaching, gym, art NO.13[2002]).

[2] Edit group of Natural dialectics notes, Natural dialectics notes. Beijing, People Education Press,1979.

[3] Huo Xiaoguang, Gao Peng. Xi Jinping visit Chinese sports delegation of Nanjing Youth Olympic Games, Xinhua net ,August 15. 